\title{
Design and Development of Secured Data Transfer System in Li-Fi
}

\author{
K. Narasimha Raju, Dekka Satish, Koduru Suresh, Bonu Satish, Dasari Manendra Sai
}

\begin{abstract}
The internet users are exponentially increasing day by day with a heavy load on spectrum. Li-Fi - a new trending technology opened the doors for communication with high speed. It is a visible light communication to transmit or receive data. The protection of data from unauthorized users is highly needed in this communication in its vicinity. Existing algorithms provides security but it involves lot of processing time which is higher than the communication time. Therefore, light weight algorithms are very much in demand. In this paper, a new light weight security mechanism is presented to avoid the access from others. The proposed mechanism provides better security in Li-Fi communication with high speed for future networks.
\end{abstract}

Keywords: Li-Fi, Light weight algorithm, Security.

\section{INTRODUCTION}

$\mathrm{Li}-\mathrm{Fi}$ is a visible light communication system that is capable of transmitting data at high speed over the visible light spectrum, ultraviolet and infrared radiation. Using light to transmit data allows Li-Fi to offer several advantages like higher bandwidth, less electromagnetic interference and high transmission speeds. Data crossing in its vicinity requires security to avoid access from other parties.

\section{II.RELATEDWORK}

Harald Haas et.al [3] gave a clear difference between VLC and LiFi. They coined the significance of LiFi in the era of Internet of Thing and 5G communications. Shivaji Kulkarni et.al [4] presented a survey on Li-Fi Technolgy and gave the importance of Li-Fi in internet users. . Nidhi Soni et.al [5] illustrated the latest technology- "LiFi" and outlined the importance of LiFi over Wi-Fi. They demonstrated the utilization of LEDs to transmit the data at higher speeds.

Revised Manuscript Received on February 05, 2020.

* Correspondence Author

Dr. K. NarasimhaRaju *,CSE Department, LENDI ,Viziangaram, AP, India.E-mail:bcoolmind@gmail.com

Dekka Satish, CSE Department, LENDI, Viziangaram, AP, India. E-mail:satishmtech4u@gmail.com

Koduru Suresh , SAP Labs Bangalore, India. E-mail: koduru112@gmail.com

Bonu Satish , CSE Department, LENDI, Viziangaram, AP, India. E-mail: vsp.satish@gmail.com

Dasari Manendra Sai ,CSE Department, Sai Ganapathi Engineering College,AP, India.E-mail: sgec.csehod@gmail.com

(c) The Authors. Published by Blue Eyes Intelligence Engineering and Sciences Publication (BEIESP). This is an open access article under the CC BY-NC-ND license (http://creativecommons.org/licenses/by-nc-nd/4.0/)
R.Mahendran [6] concentrated on sending multimedia traffic using LEDs in Communication which is nothing but communication through illumination V.K.G. kalaiselvi et.al [7] utilized the LiFi communication capability in traffic lights for sending the data. They updated the drivers through basic available information. Zubin Thomas et.al [8] provided a solution for billing in the large super markets using $\mathrm{LiFi}$. They considered the process of integration between the mobile phone and products. They reduce the time to be spent for the customers for billing. Monica Leba et.al [9] elaborated some of the advantages and applications of LiFi over wifi. They coined that Lifi provides some solutions where there are many issues of WiFi.

The above literatures mainly deal with transmission of data in $\mathrm{LiFi}$ and applications of $\mathrm{LiFi}$ ignoring the concept of security of data in their vicinity.

\section{METHODOLOGY}

The data transmission speed in Wi-Fi is relatively low. Li-Fi uses LED for data transmission with a high speed with a less radio emissions. Li-Fi technology opened the doors for communication with high speed using visible light communication for data transmission. The protection of data from unauthorized users is highly required in its vicinity. Secured data transmission is a challenging issue. Existing algorithms provides security but it involves lot of processing time which is higher than the communication time. Therefore light weight algorithms are to be designed in view of their processing capabilities. The design of the communication system with Light Weight Security algorithm for $\mathrm{Li}-\mathrm{Fi}$ (LWSAL) is shown in the figure 1.

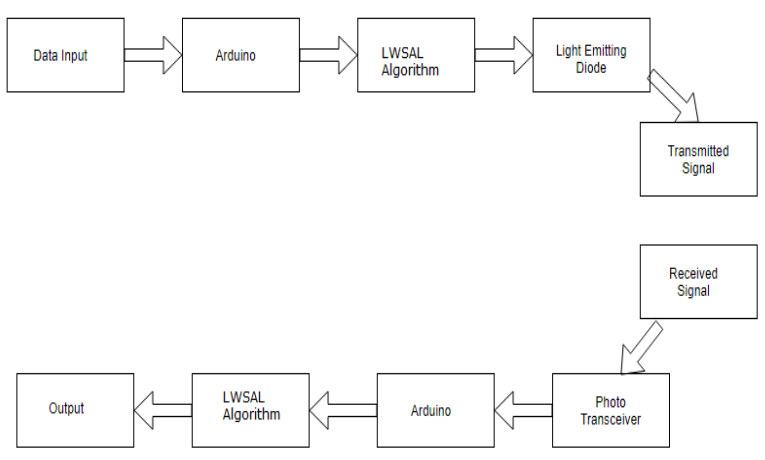

Fig1.DesignLWSAL Algorithm

Published By:

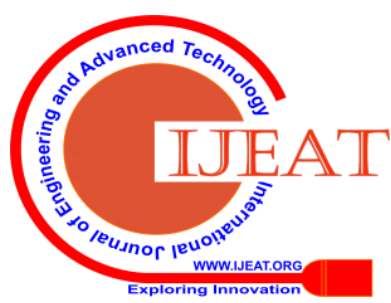


Step 1: Read Input character by character.

Step 2: K=position of the character;

Step 3: $\mathrm{x}=$ ASCII value of the character;

Step 2: Encryption is done by using Caesar Cipher algorithm.

$$
E(x)=(x+K) \bmod 256
$$

Step 3: Conversion of char to Binary.

Step 4: Transmitted Signal.

Step 5: Received Signal.

Step 6: Conversion of Binary to char.

Step 7: Decryption is done by using

$$
\mathrm{D}(\mathrm{x})=(\mathrm{E}(\mathrm{x})-\mathrm{K}) \bmod 256
$$

Step 8: Output.

Example: Suppose the data to be transmitted is 'hello'. The following actions take place at the sender and receiver side.

Assume the character values (x) for H,E,L and $\mathrm{O}$ are 72 , position values $(\mathrm{k})$ of $\mathrm{h}$ is 1 , e is 2 , first $\mathrm{l}$ is 3 , second $\mathrm{l}$ is 4 and o is 5 .

\section{At Sender:}

$\mathrm{H}$ can be encoded as $\mathrm{E}(\mathrm{x})=(\mathrm{x}+\mathrm{k}) \% 256=(72+1) \% 256=$ $73 \% 256=\mathrm{I}$

E can be encoded as $\mathrm{E}(\mathrm{x})=(\mathrm{x}+\mathrm{k}) \% 256=(69+2) \% 256=$ $71 \% 256=\mathrm{G}$

$\mathrm{L}$ can be encoded as $\mathrm{E}(\mathrm{x})=(\mathrm{x}+\mathrm{k}) \% 256=(76+3) \% 256=$ $79 \% 256=0$

$\mathrm{L}$ can be encoded as $\mathrm{E}(\mathrm{x})=(\mathrm{x}+\mathrm{k}) \% 256=(76+4) \% 256=$ $80 \% 256=\mathrm{P}$

$\mathrm{O}$ can be encoded as $\mathrm{E}(\mathrm{x})=(\mathrm{x}+\mathrm{k}) \% 256=(79+5) \% 256=$ $84 \% 256=\mathrm{T}$

At Receiver:

I can be encoded as $\mathrm{D}(\mathrm{x})=(\mathrm{E}(\mathrm{x})-\mathrm{k}) \% 256=(73-1)$ $\% 256=72 \% 256=\mathrm{H}$

$\mathrm{G}$ can be encoded as $\mathrm{E}(\mathrm{x})=(\mathrm{E}(\mathrm{x})-\mathrm{k}) \% 256=(71-2)$ $\% 256=69 \% 256=\mathrm{E}$

$\mathrm{O}$ can be encoded as $\mathrm{E}(\mathrm{x})=(\mathrm{E}(\mathrm{x})-\mathrm{k}) \% 256=(79-3)$ $\% 256=76 \% 256=\mathrm{L}$

$\mathrm{P}$ can be encoded as $\mathrm{E}(\mathrm{x})=(\mathrm{E}(\mathrm{x})-\mathrm{k}) \% 256=(80-4)$ $\% 256=76 \% 256=\mathrm{L}$

$\mathrm{T}$ can be encoded as $\mathrm{E}(\mathrm{x})=(\mathrm{E}(\mathrm{x})-\mathrm{k}) \% 256=(84-5)$ $\% 256=79 \% 256=0$

\section{RESULT AND ANALYSIS}

The above system was implemented taking the two arduino boards for sender and receiver connected with LEDs which is shown in the figure 2. Since homes and offices already have LED bulbs for lighting purposes, the same source of light can be used to transmit data. Hence, it is very efficient in terms of costs as well as energy. LED consumes very little power. The Table 1 provides a comparison of proposed work with existing technologies.

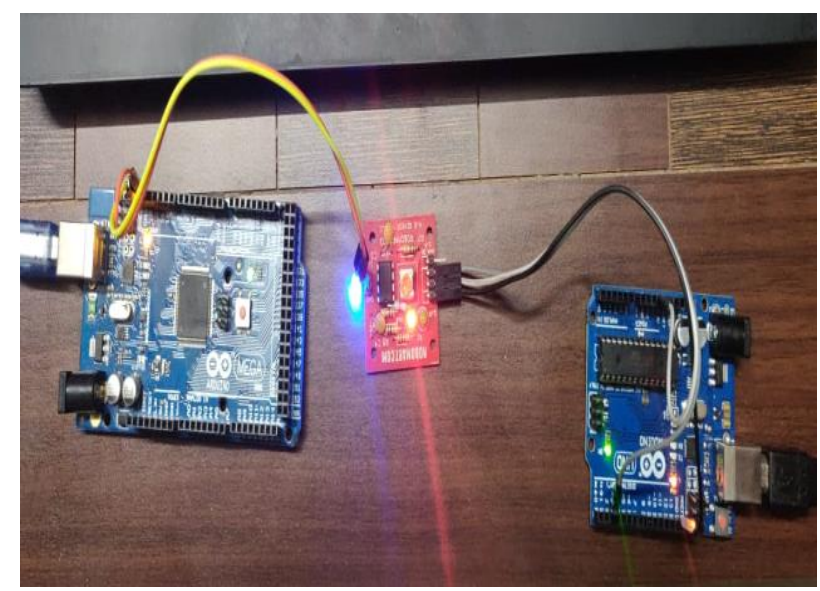

Fig 2. Illustration of LiFi communication

Table 1

\begin{tabular}{|c|c|c|}
\hline & LWSAL & RSA \\
\hline Power consumption & Less & High \\
\hline Complexity & Less & High \\
\hline Environment friendly & High & Less \\
\hline
\end{tabular}

\section{CONCLUSION AND FUTURE SCOPE}

The concept of Li-Fi is currently attracting a lot of eye-balls because it offers a genuine and very efficient alternative to radio based communication. Data can be transmitted very quickly through Li-Fi in a secured manner with the addition of security feature through LWSAL work. The proposed work is simple, energy efficient and cost effective. In future, it can be extended to large geographical areas.

\section{REFERENCES}

1. Pavan Joshi, Shivaji KulKarni, Amogh Darekar, "A survey on Li-Fi technology" in proc of International Conference on Wireless Communications, Signal Processing and Networking (WiSPNET), 2016.

2. Vasu Dev Mukku, Sebastian Lang, Tobias Reggelin, "Integration of LiFi Technology in an Industry 4.0 Learning Factory", Procedia Manufacturing, Elsevier, Volume 31, pages 232-238, 2019.

3. Harald Haas, Liang Yin, Yunlu Wang and Cheng Chen, "What is Li?", Journal of Lightwave Technology, IEEE, Volume 34, Issue 6, pages 1533-1544, March , 2016.

4. Shivaji kulkarni, Amongh Darekar and Pavan Joshi, "A survey on $\mathrm{Li}-\mathrm{Fi}$ technology", In proceedings of International Conference on Wireless communications, Signal Processing and Networking, IEEE, March 2016

5. Nidhi Soni, Mayank Mohta, Tanupriya Choudhury, "The looming visible light communication Li-Fi: An edge over Wi-Fi", In proceedings of International Conference system modeling \& Advancement in Research Trends (SMART), IEEE, November 2017.

6. R.mahendran, "Integrated LiFi(Light Fidelity) for smart communication through illumination ", International conference on Advanced Communication Control and Computing Technologies, IEEE, may 2016.

7. V.K.G.Kalaiselvi, A.Sangavi and Dhivya, "Li-Fi technology in traffic light", In proceedings of 2nd International Conference on Computing and Communication Technologies, IEEE, Feb 2017. 
8. Zubin Thomas, Nikil Kumar, D Jyothi Preshiya, "Automatic billing system using Li-Fi module", in proc of International Conference on Communication and Signal Processing (ICCSP), 2016.

9. Monia Leba, Simona Riurean, Andreea Lonica, "LiFi-The path to a new way of communication", 12th Iberian Conference on Information system and Technologies, IEEE, June 2017.

\section{AUTHORS PROFILE}

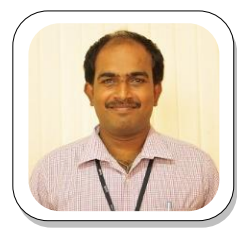

Dr. K. NarasimhaRaju,Professor, CSE Department LENDI, Viziangaram, Expertise and interest include: Computer Networks, Mobile Ad-hoc Networks \& Soft Computing.

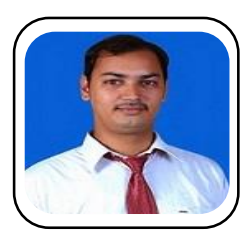

Satish Dekka, M.Tech., (Ph.D.),Associate Professor, CSE Department, Lendi ,Vizianagaram. Expertise and interest Include:Computer Networks, Wireless Sensor networks \& internet of things(IoT).

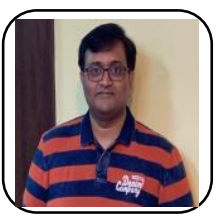

Koduru Suresh, M.Tech.,(Ph.D.), SAP Labs Bangalore, India. Expertise and interest include: Computer Networks, internet of things (IoT) \& Software Development.

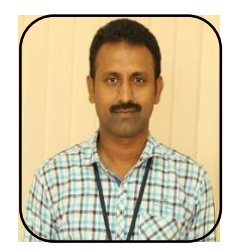

Bonu Satish, M.Tech.,(Ph.D.),Associate Professor, CSE Department, Lendi ,Vizianagaram.Expertise and interestInclude:ComputerNetworksSecurity,MANET

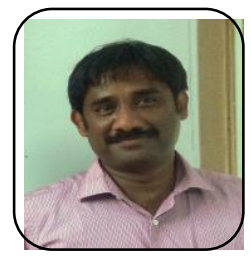

Dasari Manendra Sai *, M.Tech.,(Ph.D.), Associate Professor, CSE Department, SGEC,Expertise and interest include: Computer Networks, Cyber Security. 